\title{
Consideraciones sobre la memoria y el olvido en la filosofía de Friedrich Nietzsche
}

\author{
Kevin Iván Vanioff \\ Universidad Nacional del Nordeste (Argentina) \\ ivan_vanioff@hotmail.com
}

Recibido: 9/06/2015

Aceptado: 20/08/2015

Resumen:

Este artículo se centra en el tema de la relación entre la vida, la memoria y el olvido en el pensamiento nietzscheano. El desarrollo teórico pretende mostrar que la memoria no sólo enferma la vida, sino que también la potencia y que el olvido no siempre se identifica con la salud, sino también con la debilidad. Se pondrá en evidencia la complejidad con que se presentan estos dos fenómenos en la filosofía de Nietzsche mostrando las divergencias existentes en torno de las relaciones con lo vital. A partir de allí, se concluye con una resignificación de la memoria y el olvido a la luz de las nuevas relaciones posibles con la vida.

Palabras claves: Nietzsche, Memoria, Olvido, Vida, Pasado

Abstract:

This article focuses on the issue of the relationship between life, memory and forgetfulness in Nietzsche's thought. The theoretical development wants to show that memory is not only sick life, but also the power and that forgetting is not always identified with health but also with weakness. These phenomena are complex and exhibit differences in their relations with life. From there, it is concluded with a redefinition of memory and forgetting in the light of possible new relations with life. 
Keywords: Nietzsche, Memory, Forget, Life, Past

\section{1.- Introducción}

El presente trabajo se propone abordar la obra de Friedrich Nietzsche para identificar los diferentes sentidos que el autor atribuye a la memoria, el olvido y su relación con la vida. El filósofo alemán no ha hecho un tratamiento exclusivo respecto a este tema, pero es posible inferir algunas definiciones a partir de aforismos de distintas obras y sobre diversos temas. Comprendo a la memoria como la invasión del pasado sobre el presente, como ejercicio de la voluntad presente volcada hacia el pasado, en tanto que el olvido se lo entiende como suspensión y omisión de impresiones sobre la vida. Asimismo, ambas facultades son entendidas como procesos que emergen tanto en el cuerpo orgánico como en el cuerpo social, en el individuo y en la comunidad. Este trabajo retoma las investigaciones realizadas por el Prof. Guillermo Vega en su tesis de licenciatura donde trabaja exclusivamente esta temática.

Quizá el intento mejor logrado en abordar el fenómeno de la memoria y el olvido se da en La Genealogía de la Moral. En el segundo tratado de esta obra ambas facultades se presentan como contrarias, identificando la memoria con las fuerzas reactivas negadoras de la vida y el olvido con las fuerzas activas que afirman el potencial vital. Deleuze retoma esta lectura y Niemeyer la plasma en su diccionario sobre Nietzsche al definir estas dos capacidades mediante la identificación de la enfermedad con memoria y la salud con el olvido. Considero que esta interpretación es insuficiente ya que no da cuenta de los otros sentidos que Nietzsche le atribuye a estos dos elementos en otras obras. Por esta razón, este trabajo recurre a la Segunda Consideración Intempestiva y Sobre Verdad y Mentira en Sentido Extramoral para señalar la existencia de otras relaciones posibles entre la memoria, el olvido y la vida que van más allá, en incluso divergen, de la presentada en la Genealogía de la Moral. En el segundo capítulo se abordará el problema de la historia para a partir de allí realizar algunas distinciones sobre los usos del pasado para mostrar que la historia no siempre enferma la vida, como 
sostiene Deleuze sino que puede potenciarla. En el tercer capítulo se verá la existencia de diversas formas de olvido, que contrariamente a la lectura deleuziana, debilitan la vida. En el último apartado se hacen algunas consideraciones preliminares evidenciando una complejización de la relación entre memoria, olvido y vida.

\section{2.- Memoria y Olvido en La Genealogía de la Moral}

Nietzsche publica La Genealogía de la Moral. Un escrito polémico en el año 1887. En el mismo retoma la línea de Humano, Demasiado Humano en lo que respecta al estudio y crítica de los prejuicios morales y su relación con la vida. La particularidad de esta obra reside en el hecho de que el autor hace uso explícito de un modo específico de abordar la problemática: la genealogía. En el prólogo el filósofo plantea su propuesta de la siguiente manera:

necesitamos una crítica de los valores morales, hay que poner alguna vez en entredicho el valor mismo de esos valores $-\mathrm{y}$ para esto se necesita tener conocimiento de las condiciones y circunstancias de que aquellos surgieron y en las que se desarrollaron. ${ }^{1}$

La cuestión de la memoria y el olvido adquiere relevancia en los tres primeros aforismos del segundo tratado, que se inserta dentro del problema general sobre el origen del sentimiento de culpa y de la mala conciencia. El tratamiento que Nietzsche hace de la memoria y el olvido en este texto constituye una de las principales referencias a la hora de abordar un análisis sobre estas dos facultades. Una de las razones de que esto suceda es que en esta obra la memoria y el olvido se presentan como dimensiones claramente opuestas y contradictorias en relación a la vida. Ya en el primer tratado Nietzsche había indicado que en todo valor se origina a partir de la relación entre fuerzas activas y reactivas. Las primeras aspiran a dominar, a imponerse, a extenderse, a afirmar la diferencia, a separarse, a decir sí a la vida, mientras que las segundas tienden a garantizar su conservación, a reprimirse y negar la vitalidad. Es en esta relación entre

\footnotetext{
${ }^{1}$ NIETZSCHE, La genealogía de la moral. Trad. Andrés Sánchez Pascual. Madrid, Alianza, 1975 p. 23.
} 
fuerzas donde los conceptos de memoria y olvido se insertan en la trama teórica de la obra.

El olvido aparece como una facultad activa y que constituye lo esencial de la primitiva animalidad humana que ha sido interrumpida en los casos en que hay que hacer promesas y producir memoria. Olvidar significa "cerrar de vez en cuando las puertas y ventanas de la conciencia" ${ }^{2}$ para que haya lugar para el surgimiento de lo nuevo y de funciones más nobles, "éste es el beneficio de la activa, como hemos dicho, capacidad de olvido, una guardiana de la puerta, por así decirlo, una mantenedora del orden anímico". 3 El olvido es una condición esencial para el desarrollo de una actividad vital saludable ya que inaugura un espacio caracterizado por la ausencia de huellas mnémicas que interfieran los procesos de innovación y creación de sentido. El olvido genera un estado anímico en el que se suspende la integración y asimilación de conocimientos para favorecer la aparición de la novedad mediante el despliegue de las fuerzas activas. Asimismo, el olvidar es una facultad primitiva que permite la percepción temporal del presente, en el sentido de que la actualidad no se ve invadida por elementos o huellas del pasado, en este sentido es sumamente positiva para la vida "hay una sobreabundancia de fuerza plástica, remodeladora, regeneradora, fuerza que también hace olvidar" ${ }^{4}$ Según Vanessa Lemm, esta saludable facultad de olvidar configura el temple necesario gracias al cual el "individuo soberano" puede superar la "memoria de la voluntad" que fue impresa a través del dolor suplantándola por una activa capacidad de hacer promesas mediante la afirmación de su palabra. ${ }^{5}$

En la Genealogía de la Moral, el tratamiento que Nietzsche hace de la memoria es más extenso, ya que se relaciona directamente con otros conceptos como ser la conciencia, la culpa y los ideales ascéticos, que son elementos centrales de la obra y son desarrollados con mayor detalle. Para el filósofo, la memoria se origina como instancia

\footnotetext{
${ }^{2}$ Ibíd. Pág. 66.

${ }^{3}$ Ibídem.

${ }^{4}$ Ibíd. Pág. 45.

${ }^{5}$ LEMM, Vanessa. "Memory and Promise in Arendt and Nietzsche" en Revista de Ciencia Política. Vol. 26, N 2, 2006, pág. 166.
} 
que suspende el natural olvido del animal humano en el momento en que se ha de prometer:

precisamente este animal olvidadizo por necesidad, en el que el olvidar representa una fuerza, una forma de la salud vigorosa, ha criado en si una facultad opuesta a aquella, una memoria con cuya ayuda la capacidad de olvido queda en suspenso en algunos casos, -a saber, en los casos en que hay que hacer promesas. ${ }^{6}$

Uno de los temas centrales del segundo tratado es la cuestión de cómo producir un animal al que le sea lícito prometer. Para poder realizar esta tarea, el hombre primero debe volverse regular y calculable, de modo tal que entre la manifestación de querer y la auténtica descarga de la voluntad puedan interponerse diversas circunstancias sin que por ello la realización de la promesa se vea alterada. De este modo, lo que se genera es una memoria de la voluntad, esto quiere decir, un no querer volver a liberarse, un seguir y seguir queriendo lo querido.

Para lograr instalar una memoria en el animal hombre se necesita implementar un procedimiento mnemotécnico basado en el dolor, en esto Nietzsche es claro: "para que algo permanezca en la memoria se lo graba a fuego; solo lo que no cesa de doler permanece en la memoria". ${ }^{7}$ El dolor constituye entonces la condición de posibilidad del surgimiento de la memoria. Para crear una memoria en el animal hombre es necesario utilizar procedimientos basados en el dolor, de esta manera se logra imprimir en el organismo una serie de preceptos que logran regular la conducta y los afectos del hombre, volviéndolo así capas de prometer y recibir promesas. El dolor es entonces el componente que liga la memoria con los ideales ascéticos:

todo esto tiene su origen en aquel instinto que supo adivinar en el dolor el más poderoso medio auxiliar de la mnemónica. En cierto sentido toda la ascética

\footnotetext{
${ }^{6}$ NIETZSCHE, Friedrich. La Genealogía de la Moral. Op. Cit., Pág. 66.

${ }^{7}$ Ibíd. Pág. 69.
} 
pertenece a este campo: unas cuantas ideas deben volverse imborrables, omnipresentes, inolvidables, «

Los ideales ascéticos son tratados con exclusividad en el tercer tratado de $L a$ Genealogía de la Moral, pero es un tema recurrente en la obra de Nietzsche, ya que en ellos se observa claramente la relación entre el cuerpo y los ideales metafísicos. Las prácticas ascéticas remiten a una espiritualización y domesticación de los instintos e impulsos vitales del cuerpo con el fin de reprimirlos para alcanzar un estado de conciencia superior. Pero vale recordar que para Nietzsche "todos los instintos que no se desahogan hacia fuera se vuelven hacia dentro (...) únicamente con esto se desarrolla en él lo que más tarde se denomina su «alma»" ${ }^{\prime 9}$, por esta razón el dolor producido por la represión de instintos llevado a cabo por la puesta en práctica de los ideales ascéticos llevan a instalar y reforzar una memoria de la voluntad en el cuerpo.

Se ha visto que en La Genealogía de la Moral la memoria es una facultad reactiva instaurada mediante el dolor de las prácticas ascéticas para dominar los instintos y domesticar al animal humano, en tanto que el olvido representa una dimensión activa y noble que permite el surgimiento de nuevas formas y sentidos. En esta obra se da una clara oposición entre ambas facultades, de allí que sea a partir de este texto que algunos comentaristas hacen el estudio de dichos conceptos.

Gilles Deleuze publica Nietzsche y la Filosofía en el año 1962. En esta obra la memoria y el olvido son interpretadas según la oposición que Nietzsche establece en La Genealogía de la Moral: "El tipo del señor (tipo activo) vendrá definido por la facultad de olvidar, así como por el poder de activar las reacciones. El tipo del esclavo (tipo reactivo) vendrá definido por la prodigiosa memoria, por el poder del resentimiento“. ${ }^{10}$ En dicha obra, Deleuze se esfuerza por interpretar el corpus nietzscheano en términos de relaciones entre fuerzas activas y reactivas, de allí que al tocar el tema de la memoria y el olvido lo haga estableciendo ligaciones con las mismas. La memoria es entendida como

\footnotetext{
8 Ibíd. Pág. 70.

${ }^{9}$ Ibíd. Pág. 96.

${ }^{10}$ DELEUZE, G. Nietzsche y la filosofía. Trad. Carmen Artal. Barcelona, Anagrama, 1971. Pág.165.
} 
trazas mnémicas reactivas que se corresponden, con el espíritu de venganza, ${ }^{11}$ con el resentimiento, ${ }^{12}$ con la culpa y la impotencia. ${ }^{13}$ Mientras que el olvido es presentado como una actividad supraconciente ${ }^{14}$ al que la historia de la filosofía siempre le atribuyó un carácter negativo, pero que en realidad representa la afirmación de las potencias activas de la vida. Si bien esta obra no se dedica exclusivamente al tema de la memoria y el olvido, uno puede observar que cuando Deleuze aborda dichas temáticas utiliza exclusivamente La Genealogía de la Moral como referencia bibliográfica. De allí, que el tratamiento que hace de estos elementos resulte parcial e insuficiente porque no contempla los diversos sentidos atribuidos por Nietzsche en otras obras, que en algunos casos, como veremos más adelante, pueden entrar en contradicción con la interpretación deleuziana de los mismos.

Por su parte, esta interpretación que identifica la memoria con las fuerzas reactivas y el olvido con las fuerzas activa tiene su correlato en el Diccionario Nietzsche publicado en el año 2012 por Christian Niemeyer. En dicha obra la memoria y el olvido se vuelven a presentar como elementos opuestos, mientras que el primero enferma el cuerpo, el segundo le devuelve la salud. ${ }^{15}$

Hasta aquí se ha hecho una descripción de la relación entre la memoria y el olvido respecto a la vida que se da en la Genealogía de la Moral mientras lo primero tiende a debilitarla, lo segundo la potencia. Se ve como esta obra se constituye como la principal referencia a la hora de abordar ambas facultades. A continuación se exploran dos obras donde el sentido atribuido diverge de lo expuesto hasta aquí.

\section{3.- La memoria y el olvido abordado a través de las concepciones nietzscheanas sobre la historia}

\footnotetext{
${ }^{11}$ Cfr., Ibíd. Pág. 175.

${ }^{12}$ Cfr., Ibíd. Pág. 162.

${ }^{13}$ Cfr., Ibíd. Pág. 164.

${ }^{14} \mathrm{Cfr} .$, Ibíd. Pág. 160.

${ }^{15}$ Cfr., NIEMEYER, Christian. Diccionario Nietzsche. Conceptos, obras, influencias y lugares. Trad. Germán Cano. Madrid, Biblioteca Nueva, 2012, pág. 343.
} 
Sobre utilidad la utilidad y los perjuicios de la historia para la vida se publicó en 1874. El joven profesor de la universidad de Basilea se encontraba por entonces en el cénit de su entusiasmo wagneriano. Su pensamiento se dedicaba a lo que suponía era una gran renovación artística e intelectual en toda Europa y particularmente en Alemania, donde según él, dominaba la mediocridad y la arrogancia en el ámbito cultural. La obra tiene como tema central elucidar la relación que existe entre la vida y la historia, proponiendo la hipótesis de la existencia de "una forma de hacer historia y valorarla en que la vida se atrofia y degenera" ${ }^{16}$ Por ello, la sociedad de su tiempo padece lo que Nietzsche llama "enfermedad histórica", en este sentido un exceso de historicismo es considerado como un proceso que enferma y daña la vida: "trato de interpretar como un mal, una enfermedad, un defecto, algo de lo que nuestra época está, con razón, orgullosa: su cultura histórica, pues creo que todos nosotros sufrimos de una fiebre histórica devorante". ${ }^{17}$

En este texto, el problema de la memoria y el olvido puede ser inferido a partir de las reflexiones de sobre los diferentes modos de apropiarse del pasado. La interpretación que Nietzsche realiza sobre usos de la historia y su relación con la vida se enmarca dentro de una fuerte crítica de la modernidad, que se convierte en diatriba contra el estado de la cultura europea. Condena su época por haber desligado la cultura de la vida, debilitando así las potencias creadoras del hombre moderno, inutilizando sus fuerzas instintivas y neutralizando lo que hay en él de vital. La historia científica ha dejado de lado el fenómeno de la vida para convertirse en un fin en sí misma. El incremento del conocimiento histórico, característico de la época, ha permitido una invasión y acumulación de datos que producen contaminación, ${ }^{18}$ el efecto de este proceso es un bagaje de información confusa y excesiva, que resulta indigerible. De este modo, una dosis

\footnotetext{
${ }^{16}$ NIETZSCHE, F. Sobre la utilidad y los prejuicios de la historia para la vida. Trad. Dionisio Garzón. Madrid, EDAF, 2002. Pág. 32.

${ }^{17}$ Ibídem.

${ }^{18}$ Cfr., VATTIMO, Gianni. VATTIMO, G. Diálogos con Nietzsche. Trad. Carmen Revilla. Paidós, Buenos Aires, 2002, pág. 37.
} 
excesiva de historia o memoria tiene graves consecuencias sobre la vida, ya que según Nietzsche "un exceso de historia daña a lo viviente". ${ }^{19}$

En términos generales se podría afirmar que un exceso de memoria conspira en contra de la vida, pero Nietzsche sostiene que existen tres formas de relacionarse con el pasado, cuyos abusos son siempre peligrosos pero que se relacionan de manera distinta con la experiencia vital: "en tres aspectos pertenece la historia al ser vivo: en la medida en que es un ser activo y persigue un objetivo, en la medida en que preserva y venera lo que ha hecho, en la medida en que sufre y tiene necesidad de una liberación" ${ }^{20}$ De estas tres formas de relacionarse con lo pretérito surgen los tipos de historia: la historia monumental, la historia anticuaria y la historia crítica. Cada una posee singularidades que la definen como formas específicas de relacionarse con el pasado según la disposición actual de la fuerza vital del individuo. A continuación se desarrollará cada concepción de historia señalando las características principales de su relación con la vida para a partir de allí inferir un concepto de memoria.

Primero tenemos al hombre superior, el genio artista, el poderoso militar, ellos son los ejemplos de usuarios de la historia monumental. El gran hombre tiene la intención de emplear los grandiosos hechos pasados para utilizarlos como ejemplo para su acción en el presente. En este modo de apropiarse del pasado "la historia pertenece, sobre todo, al hombre de acción, al poderoso, al que libra una gran lucha y tiene necesidad de modelos, de maestros, de confortadores, que no puede encontrar en su entorno ni en la época presente". ${ }^{21}$ Por lo tanto, se observa en la historia monumental que la condición previa de su expresión es una constitución vital fuerte y saludable que se apropia del pasado para potenciar su actividad actual. Existe en esta interpretación del pasado cierta expresión de valores heroicos que sirven como modelos de referencias que se enmarcan para dar sentido a la acción en el presente. Esto es posible gracias a la suposición de que "la grandeza que un día existió fue, en todo caso, una vez posible y, sin duda, podrá, otra

\footnotetext{
${ }^{19}$ NIETZSCHE, F. Sobre la utilidad y los prejuicios de la historia para la vida. Op. Cit., pág. 49.

${ }^{20}$ Ibíd. Pág. 49.

${ }^{21}$ Ibídem.
} 
segunda vez," 22 pero para poder lograr esto primero es necesario realizar analogías entre el presente y el pasado con el fin de equiparar los hechos históricos con el presente. Aquí es donde aparece uno de los peligros de la historia monumental, el de forzar la historia para hacerla concordar con los propósitos y finalidades que se persigue, Nietzsche advierte sobre este peligro: “ide qué manera forzada habría que hacer entrar la individualidad del pasado en un molde general, recortando ángulos y líneas relevantes, en beneficio de la homología!". ${ }^{23}$ Existe en la historia monumental un abuso hermenéutico que consiste en interpretar la historia para llevar a cabo la legitimización de acciones presentes, de esta manera los poderosos se servirán del pasado para posicionarse a sí mismos como herederos de antiguos próceres. Por lo tanto, se tiende a deformar el pretérito, no se pretende la objetividad porque "la historia monumental no tendrá necesidad de esa plena veracidad: siempre acercará, generalizará y, finalmente, igualará cosas que son distintas". ${ }^{24}$ Por lo tanto, es posible afirmar que la memoria de historia monumental se basa en una constitución vital poderosa que lejos de buscar la objetividad, tiende a deformar el pasado para ajustarlo a sus fines. $Y$ es en esta deformación del pasado que se revela una acción creativa expresada en la intención de ajustar la historia al presente. En este caso la memoria juega un papel activo, que además de proponer modelos de acción reconocidos como heroicos también realiza una tarea hermenéutica ligada a la creación estética, Nietzsche reconoce esta intención poietica al decir que "mientras el pasado tenga que ser descrito como digno de imitación, como imitable y posible otra segunda vez, incurre, ciertamente, en el peligro de ser distorsionado, de ser embellecido, y se acerca así a la pura invención poética ${ }^{25}$." Se observa entonces que en la historia monumental la vida no es puesta al servicio de la historia, sino más bien lo contrario, es la historia la que se presta a la manipulación por parte de los vitalmente poderosos. La vida ascendente se sirve del pasado para continuar con su expansión y dominio a costa de deformar el pasado, por ello "cuando un hombre que desea realizar

\footnotetext{
22 Ibíd. Pág. 52.

23 Ibíd. Pág. 53.

24 Ibíd. Pág. 54.

25 Ibíd. Pág. 55.
} 
algo grande tiene necesidad del pasado, se apropia de él mediante la historia monumental ${ }^{26}$." La memoria responde aquí a las fuerzas afirmadoras y activas de la vida.

La segunda manera de relacionarse con el pasado propuesta por Nietzsche es la historia anticuaria. Aquí el hombre busca enraizarse en una tradición, necesita encontrar en el conocimiento del pasado una identidad que lo defina y le dé seguridad. A diferencia de la historia monumental donde es el sujeto quien se apodera del pasado, en la historia anticuaria "la posesión del patrimonio ancestral toma un sentido diferente porque, en lugar de poseer el alma estos objetos, está poseída por ellos," ${ }^{27}$ por esto se puede sostener que existe en esta modalidad de apoderase del pasado una función más pasiva. Pero también hay otra característica que la diferencia de la historia monumental y que revela cierta debilidad vital en aquellas que optan por esta forma de historia, dice Nietzsche que "todo lo que es pequeño, limitado, decrépito y anticuado recibe su propia dignidad e intangibilidad por el hecho de que el alma del hombre anticuario, tan inclinada a preservar y venerar, se instala en estas cosas y hace en ellas un nido familiar" ${ }^{28}$ En este fragmento se puede notar que la preservación y veneración que del pasado hace la historia anticuaria constituye una especie de morada en la que el habitante derruido puede ser acogido para garantizar su existencia. De tal modo, la memoria que se ejerce en esta modalidad tenderá siempre al anquilosamiento de las condiciones pasadas que se necesitaron para conservar la vida, por eso es posible inferir que la forma de vida del anticuario no se basta a sí misma para subsistir, sino que necesita aferrarse a sus condiciones de posibilidad por medio de la historia.

Según Nietzsche, los que prefieren la historia anticuaria poseen condiciones de existencias desfavorables que lo mueven a aferrarse al pasado con la finalidad de dar un sentido a su "modesta, ruda y penosa" existencia. Se ha dicho hasta aquí que el historiador anticuario preserva y venera el pasado en pos de garantizar sus condiciones favorables de existencia porque padece una debilidad vital. Pero a esto hay que sumar

\footnotetext{
${ }^{26}$ Ibíd. Pág. 58.

27 Ibíd. Pág. 59.

${ }^{28}$ Ibídem.
} 
una conducta que también es promovida por esta forma de hacer historia y sirve para conservar la vida, esto es la identificación del individuo con el grupo o como lo llama Nietzsche en otras obras, el instinto gregario. El historiador anticuario tiende a identificarse por medio de la historia con un grupo humano que comparte el pasado. ${ }^{29}$ Lo que se revela entonces es una dinámica reactiva proclive a establecer una vida en grupo, pero esta necesidad de historia común es "lo que empuja al individuo a aferrarse a un grupo o a un ambiente, a unos cansados hábitos, a unas peladas colinas, puede parecer obstinación e ignorancia -pero es la ignorancia más saludable y beneficiosa para la colectividad" ${ }^{30}$ Por lo tanto, la historia anticuaria es propensa a fomentar la vida colectiva mediante el establecimiento de una historia común que garantiza la conservación de la comunidad. Pero si bien esto es beneficioso para el grupo puede no serlo tanto para los hombres de acción que, teniendo una salud poderosa, pueden prescindir de la colectividad para desarrollar su potencial vital. $Y$ aquí se presenta uno de los principales peligros del exceso de historia anticuaria, inhibir a los hombres independientes que se bastan a sí mismos en los que las fuerzas vitales aumentan de tal modo que exigen su expresión mediante la producción de la novedad. El historiador anticuario es un especialista en la preservación de la vida pero por su debilidad le está imposibilitado la capacidad creativa, Nietzsche es claro cuando dice que "la historia anticuaria sabe solo cómo conservar la vida, no cómo crearla". ${ }^{31}$ Por lo tanto, el anticuario es un hombre inmovilizado en el que la vida se ve suspendida en una atmósfera que la conserva pero que no promueve la aparición de nuevas formas de comprender el presente y el pasado, por esto "la historia anticuaria impide el optar resueltamente por lo nuevo, paraliza al hombre de acción". ${ }^{32}$ Esta actitud paralizante tiene como objetivo impedir la creación de la vida porque proponer una nueva interpretación de la historia pondría en peligro las condiciones que garantizan la conservación de una vida debilitada que necesita refugiarse

\footnotetext{
${ }^{29}$ Cfr., lbíd. Pág. 60.

${ }^{30}$ Ibíd. Pág. 61.

${ }^{31}$ Ibíd. Pág. 64.

${ }^{32}$ Ibídem.
} 
en el pasado y en la colectividad para dar sentido a su pobre existencia. Este es el principal peligro que existe cuando se abusa de la historia anticuaria

cuando la sensibilidad de un pueblo se petrifica de tal suerte, cuando la historia sirve al pasado hasta el punto de debilitar la vida presente y, especialmente, la vida superior, cuando el sentido histórico ya no conserva la vida sino que la momifica, entonces el árbol muere de modo no natural, disecándose gradualmente desde la cúpula hasta las raíces -y, generalmente, estas acaban por morir a su vez. La historia anticuaria degenera en el momento mismo en que ya no está animada e inspirada por la fresca vida del presente. ${ }^{33}$

De este modo, Nietzsche advierte claramente que el abuso de la historia anticuaria es más perjudicial a la vida que el exceso de la historia monumental ya que su modo de existir requiere necesariamente que las fuerzas vitales productoras de lo nuevo se vean afectadas negativamente para no poner en peligro la continuación de la vida en comunidad. Por lo tanto, se puede afirmar que en la historia anticuaria la memoria tiene una función reactiva y pasiva ya que no produce lo nuevo ni tampoco tiene a apoderarse de la historia para desarrollar su potencial actual, sino más bien se contenta con la conservación del pasado para garantizar la continuidad de la vida.

Finalmente, la tercera forma de memoria corresponde al historiador crítico, este es el hombre que se siente oprimido en el presente por un pasado traumático. El que carga con un gran dolor en sus espaldas se verá en la necesidad de juzgar con dureza lo que produjo esa situación negativa con la intención final de destruirlo y así inhibir sus efectos sobre el presente.

En la historia crítica existe un ejercicio de la memoria que permite poder llevar a cabo un juicio que condene el pasado y lo destruya, pero hay que tener en cuenta que "no es la justicia quien aquí juzga; y es, todavía menos, la clemencia quien aquí pronuncia el veredicto: es solamente la vida, esa potencia oscura, impulsiva, insaciablemente ávida de

\footnotetext{
${ }^{33}$ Ibíd. Pág. 63.
} 
sí misma". ${ }^{34}$ Esto quiere decir que en la historia crítica se juzga desde una perspectiva establecida a partir de la vida y no desde un criterio axiológico que niega la vitalidad del cuerpo. La vida se presenta como una fuerza oscura que carece de forma determinada y que se quiere impetuosamente sólo a sí misma. Por esta razón, los juicios que la vida puede emitir sobre la historia nunca provienen de un criterio de valor claro, objetivo y por ello "justo", "su veredicto es siempre inclemente, siempre injusto, porque nunca procede de una pura fuente de conocimiento". ${ }^{35}$ La memoria adopta una actitud bélica que juzga la historia sin compasión y la destruye sin piedad, el juicio del historiador crítico condena duramente el pasado para desembarazarse de él, dice Nietzsche que "cuando se examina el pasado desde un punto de vista crítico, entonces se ataca con el cuchillo a las raíces, entonces se salta cruelmente sobre cualquier tipo de clemencia". ${ }^{36}$

Pero sostener una postura de confrontación con la historia puede también atentar contra la vida misma, porque atacar abiertamente la herencia histórica puede producir la extinción de la vida misma. Por otra parte, el historiador crítico se expone a los ataques de las fuerzas conservadoras que intentarán mantener la interpretación histórica vigente. Adoptar una postura crítica no es sencillo y se requiere cierta valentía para poder abordar los peligros a los que se expone, Nietzsche reconoce esto cuando dice que "este proceso es siempre peligroso, en realidad peligroso para la vida misma; y los hombres y las épocas que sirven así a la vida, juzgando y aniquilando un pasado, son siempre peligrosos y están siempre en peligro". ${ }^{37}$

La historia crítica entonces se comprende como una postura de confrontación directa donde el pasado es juzgado por la vida, la memoria se presenta como una instancia peligrosa e injusta que ve en el pasado la causa de una afección presente que perjudica a la vida. Por lo tanto, hay que destruir el pasado para lograr alcanzar un estado no invadido por impresiones pretéritas que incomodan la existencia, la memoria crítica tiene una función que libera mediante la destrucción del pasado. El hombre y los pueblos

\footnotetext{
${ }^{34}$ Ibíd. Pág. 65.

${ }^{35}$ Ibídem.

${ }^{36}$ Ibíd. Pág. 66.

${ }^{37}$ Ibídem.
} 
están constituidos por la herencia histórica que las generaciones anteriores vuelcan sobre el presente, pero esta herencia no solo transmite sus virtudes sino también sus vicios, dice Nietzsche que "somos el resultado de generaciones anteriores, somos además el resultado de sus aberraciones, pasiones y errores y, también, sí, de sus delitos" ${ }^{38}$ Esta herencia constituye lo que Nietzsche llama "primera naturaleza" o "naturaleza ancestral", esta naturaleza está constituida por las impresiones que las generaciones anteriores han dejado sobre las nuevas generaciones. Por lo tanto, la historia crítica intenta destruir y liberarse de aquellos elementos negativos heredados, pero según Nietzsche "no es posible liberarse por completo de esta cadena" ${ }^{\prime 39}$ o sea que siempre vamos a seguir siendo herederos del pasado, podemos condenar sus aberraciones y creernos libres de ellas pero esto no cambiara la condición de herederos. Si bien la liberación no es total, la memoria ejercida por la historia crítica genera "un antagonismo entre nuestra naturaleza ancestral, hereditaria, y nuestro conocimiento" ${ }^{\prime 40}$ este conflicto es resuelto cuando el conocimiento nos mueve a optar por "cultivar un nuevo hábito, un nuevo instinto, una segunda naturaleza, de forma que la primera desaparezca" ${ }^{41}$

De este modo, se puede observar que la función destructiva de la memoria ejercida por la historia crítica tiene como finalidad generar la aparición de una "segunda naturaleza", o sea, de un estado de ánimo renovado que deja de sufrir por el pasado para desarrollarse en el presente mediante la afirmación de las potencias vitales. La historia crítica permite comprender que esta "primera naturaleza" heredada que nos constituye como sujetos históricos en el pasado fue una "segunda naturaleza" que ha sido impuesta mediante una mirada crítica de la historia. Esta mirada crítica permite comprender que el devenir hermenéutico de la vida está sujeto a un proceso histórico que la va condicionando y que puede ser modificado cuando se ajusticia el pasado con un criterio vital que permite la aparición de una nueva forma de existencia.

\footnotetext{
${ }^{38}$ Ibídem.

${ }^{39}$ Ibídem.

${ }^{40}$ Ibídem.

${ }^{41}$ Ibídem.
} 
Anteriormente se ha expuesto de manera detallada cuales son los tres modos de relacionarse con la historia y cuáles son los peligros que acarrea la adopción abusiva de una de estas perspectivas por sobre otra. La "enfermedad histórica" se define entonces por una desmedida invasión del pasado sobre el presente de modo tal que las fuerzas que producen la novedad se ven inhibidas, produciendo así el debilitamiento de la vida. Nietzsche de ninguna manera propone que la historia en sí misma sea algo que promueva la debilidad vital $^{42}$, sino más bien realiza una denuncia sobre los peligros que el abuso histórico produce sobre lo viviente. Frente a esta "enfermedad histórica" Nietzsche propone dos facultades que pueden devolver la salud a los pueblos que padecen la debilitación producida por el pasado: "lo ahistórico y lo suprahistórico son los antídotos naturales contra el sofocamiento de la vida por la historia, contra la enfermedad histórica". 43

El elemento ahistórico se presenta como una instancia vital en la que la vida puede expresar plenamente aquellas fuerza que el pasado impedía que afloren, por lo tanto lo ahistórico aparece como aquello que promueve y garantiza la vida: "es semejante a una atmósfera protectora, únicamente dentro de la cual puede germinar la vida y, si esta atmósfera desaparece, la vida se extingue" ${ }^{44}$ Gracias a lo ahistórico se puede poner en suspenso la caprichosa invasión del pasado sobre la vida del presente mediante el establecimiento de una especie de clima que favorece el resurgir vital. Pero lo ahistórico también es identificado por Nietzsche como la facultad de olvidar, "con la expresión «lo ahistórico» yo designo el arte y la fuerza de poder olvidar". ${ }^{45}$ De este modo, aparece aquí el concepto de olvido como un elemento vital ligado a la manifestación de fuerzas creadoras que son las únicas que pueden afirmar el presente sin las cadenas del pasado.

El olvido, al estar asociado afirmativamente a la vida hace que el hombre pueda inventarse una propia historia gracias a la omisión del pasado que el elemento ahistórico

\footnotetext{
${ }^{42}$ Cfr., VIGNALE, Silvana. Alternativas a la historia en el pensamiento de Nietzsche. Instantes y azares. Escrituras Nietzscheanas. N 6-7, Año IX, 2009, pág. 53.

${ }^{43}$ NIETZSCHE, F. Sobre la utilidad y los prejuicios de la historia para la vida. Op. Cit. Pág. 156.

${ }^{44}$ Ibíd. Pág. 41.

${ }^{45}$ Ibíd. Pág. 155.
} 
permite. De este modo, se inaugura un modo exclusivamente estético de existir, ya que la no determinación del pasado sobre el presente permite al hombre improvisar creativamente nuevas formas de vida. Pero además, el olvido es garantía de felicidad: "tanto en el caso de la ínfima como en el de la máxima felicidad, existe siempre un elemento que hace que la felicidad sea tal: la capacidad de olvidar" ${ }^{46}$ Por lo tanto, sin el olvido el hombre no podría adquirir su bienestar existencial porque estaría condenado a repetir la herencia histórica que ha adquirido a lo largo del tiempo y que ha imposibilitado la afirmación de la vida mediante una interpretación eternizante del pasado. Para concluir, se puede decir que el factor ahistórico identificado con la facultad de olvidar tiende a suspender la "enfermedad histórica" en favor de la vida, llegando incluso a garantizar la feliz existencia de los individuos y pueblos.

\section{4.- El olvido como condición del empobrecimiento vital en Sobre Verdad y Mentira en Sentido Extramoral}

Hasta aquí hemos observado que en La Genealogía de la Moral y la Segunda Consideración Intempestiva existen varios sentidos atribuidos a la memoria y su relación con la vida, pero había una coincidencia con respecto a la facultad de olvidar, en ambas obras aparece como una instancia afirmativa que devuelve la salud vital. Sin embargo, se verá a continuación cómo en Sobre Verdad y Mentira en Sentido Extramoral la facultad de olvido se presenta con un sentido opuesto, o sea, atentando contra la vida.

En esta obra Nietzsche entiende que la racionalidad emerge de como un medio de conservación que tienen las formas de vida debilitadas para conservarse, ya que produce las ficciones necesarias para permitir continuar con la existencia: "el intelecto, como medio de conservación del individuo, desarrolla sus fuerzas principales fingiendo, puesto que éste es el medio, merced al cual sobreviven los individuos débiles" ${ }^{47}$ El intelecto es un

\footnotetext{
${ }^{46}$ Ibíd. Pág. 32.

${ }^{47}$ NIETZSCHE, Friedrich. Sobre verdad y mentira en sentido extramoral. Trad. L. Valdés y T. Orduña. Tecnos, Madrid, 1996, pág. 18.
} 
órgano más al servicio de la vida, carece de algún valor que lo distinga como una cualidad superior de la especie humana.

La racionalidad está basada en procesos lógicos que permiten demostrar la verdad o falsedad de los enunciados que corresponden a los casos reales. De este modo, la lógica se constituye como el instrumento que permite el funcionamiento de las operaciones del intelecto. Nietzsche denuncia que el origen de la razón como forma de conocimiento está estrechamente ligado a la utilidad que los juicios tienen para la vida y no como instrumento para alcanzar la verdad. El proceso de abstracción es una de las funciones principales de la razón, gracias a esta facultad se logra producir conceptos que luego son proyectados sobre la realidad para comprenderla. Dicha superstición lógica es propia de aquellos individuos debilitados que necesitan recursos para poder subsistir, y al no tener la fuerza suficiente para afirmarse deben recurrir al intelecto para lograr configurar ficciones que les permita seguir con vida. La racionalidad es una función reactiva ya que garantiza la existencia de aquellos individuos al que le está destinado la extinción por la fuerza.

La crítica nietzscheana asesta contra los principios y fundamentos de la abstracción desarticulando dicha teoría de conocimiento:

Todo concepto se forma por equiparación de casos no iguales. Del mismo modo que es cierto que una hoja no es igual a otra, también es cierto que el concepto hoja se ha formado al abandonar de manera arbitraria esas diferencias individuales, al olvidar las notas distintivas. ${ }^{48}$

Lo que aquí se observa es una concepción de olvido muy distinta a la expuesta en otros escritos. Mientras que en La Genealogía de la Moral y en la Segunda Consideración Intempestiva olvidar era una facultad sana y afirmativa, aquí aparece como la condición de posibilidad de la producción de conceptos. Es decir que olvidar las particularidades de las cosas para lograr abstraerlas y formar un concepto de ellas es una función indispensable para articular un conocimiento intelectivo. Por lo tanto, es necesario no

\footnotetext{
${ }^{48}$ Ibídem.
} 
recordar las peculiaridades para alcanzar la generalización conceptual que permite articular un sentido metafísico sobre las cosas. La petrificación de los conceptos no es posible sin ese olvido reactivo que permite la fijeza de lo abstracto, por lo que la omisión de lo particular es un elemento indisociable del intelecto, ya que sin la capacidad de no recordar este no funcionaria. Aquí se revela una función gnoseológica del olvido que sirve de condición de posibilidad de la conservación de las formas de vida debilitadas. Funciona omitiendo las particularidades de cada caso dado en la realidad por lo que se convierte en una herramienta a favor del entendimiento. En este sentido aparece como forma de omisión y de falta de atención ya que "la omisión de lo individual y de lo real nos proporciona el concepto". ${ }^{49}$ Nietzsche sostiene que esta omisión de las cualidades particulares que proporciona lo conceptual es un error porque "la naturaleza no conoce formas ni conceptos, así como tampoco ningún tipo de géneros, sino solamente una $x$ que es para nosotros inaccesible e indefinible ${ }^{50}$." La "realidad" se ve así falseada gracias al olvido y es recubierta de un carácter metafísico que pretende ocultar las diferencias.

Pero también hay en este escrito otra función de la facultad de olvidar que se liga directamente a la debilidad de la vida y se presenta en el fenómeno lingüístico. Nietzsche se sitúa dentro de una disputa bastante trillada por la tradición filosófica que es el problema de la relación del lenguaje con las cosas. ${ }^{51}$ Para Nietzsche el lenguaje no representa las cosas mismas sino que es la reproducción en sonidos de un impulso nervioso y que no permite inferir la existencia de una causa exterior al hombre:

“¿qué es una palabra? La reproducción en sonidos de un impulso nervioso. Pero inferir además a partir del impulso nervioso la existencia de una causa fuera de nosotros, es ya el resultado de un uso falso e injustificado del principio de razón. ${ }^{52}$

El error del intelecto consiste en concebir dichos impulsos como las cosas mismas. La existencia de lenguajes distintos es la comprobación de que a través de las palabras

\footnotetext{
49 Ibíd. Pág. 24.

50 lbíd. Pág. 25.

${ }^{51}$ Cfr., lbíd. Pág. 21.

52 Ibíd. Pág. 25.
} 
jamás se llega a la verdad, sino que revela las relaciones de las cosas con el hombre mismo. Nietzsche denuncia que para llegar a conformar una palabra se realizan saltos de una esfera sensitiva a otra, interpolando una representación visual para luego nombrar a esa imagen con un sonido. Pero es en estos saltos donde el olvidar cumple otra función reactiva ya que el hombre "olvida que las metáforas intuitivas originales no son más que metáforas y las toma como las cosas mismas ${ }^{53}$." Por lo tanto se necesita olvidar inconcientemente el proceso de ficcionalización que le da origen para llegar al sentimiento de verdad, las metáforas no reflejan los objetos mismos ya que son producto de impulsos nerviosos. Aquí el olvido tiene una función ontológica y lingüística, ya que permite no solo la aparición del lenguaje, sino también que constituye lo que existe a través de la confusión entre la "realidad" y sus metáforas. Nietzsche lo deja claro en las siguientes palabras:

Sólo mediante el olvido de este mundo primitivo de metáforas, sólo mediante el endurecimiento y petrificación de un fogoso torrente primordial compuesto por una masa de imágenes que surgen de la capacidad originaria de la fantasía humana, [...]gracias solamente al hecho de que el hombre se olvida de sí mismo como sujeto y, por cierto, como sujeto artísticamente creador, vive con cierta calma, seguridad y consecuencia; si pudiera salir, aunque sólo fuese un instante, fuera de los muros de esa creencia que lo tiene prisionero, se terminaría en el acto su «conciencia de sí mismo». ${ }^{54}$

Aparece en este fragmento un elemento nuevo que permite descubrir otra función reactiva que niega la vida, este es el olvido de la poiesis. El hombre que da origen a las metáforas que se ven petrificadas en el lenguaje omite y no da cuenta de su carácter de creador. El modo ilusorio de las palabras es así ocultado inconcientemente para que éstas valgan como lo verdadero. Si el individuo daría cuenta de su condición de sujeto creador las metáforas tenidas por verdaderas se revelarían como formas subjetivas impresas sobre las cosas por lo que ya no obligarían a nada. Aquí el olvido sirve para ocultar la condición

\footnotetext{
53 Ibíd. Pág. 29.

54 Ibíd. Pág. 30.
} 
existencialmente creadora del hombre al omitir que las ficciones utilizadas para ordenar el mundo no vienen de la "realidad" sino que son un producto humano, Nietzsche lo deja claro cuando dice que las "las verdades son ilusiones de las que se ha olvidado que lo son". 55

De esta manera se han expuesto las diversas funciones (lógica, lingüística y estética) en las que el olvido es una facultad profundamente negativa para la vida. Pero se podría sumar una interpretación más a este elemento y es su faz política. En Sobre Verdad y Mentira en Sentido Extramoral Nietzsche supone una especie de momento en el que los hombres disponen por debilidad de la tendencia a vivir en comunidad y para ello deciden lo que debe ser creído como verdadero para garantizar la supervivencia. ${ }^{56} \mathrm{Al}$ celebrarse dicho pacto se establece lo que ha de ser verdad y gracias a esto se garantiza la conservación de la comunidad misma.

Nietzsche, en otras de sus definiciones, dice que la verdad es "una suma de relaciones humanas que han sido realzadas, extrapoladas, y adornadas poética y retóricamente y que, después de un prolongado uso, un pueblo las considera, firmes, canónicas y vinculantes". ${ }^{57}$ Ahora bien, para que este pacto posea efectos coercitivos sobre las voluntades, en otras palabras, para que obligue y valga como verdad, es necesario que no se tenga presente su carácter de ficción. Es justamente gracias a este olvido que las metáforas producidas ejercen coacción sobre la voluntad de los integrantes de la comunidad. Si no se olvida el momento en que se han pactado como ficciones verdaderas no obligarían a nadie a creer en ellas, no habría verdad y por lo tanto tampoco comunidad. De lo que se trata ahora en más es de mentir de acuerdo a lo pactado, ya que aquél que no se adecue al uso convenido de las metáforas será condenado por la comunidad. El resultado es una constante represión de aquellas formas de vida afirmativas que despliegan su potencial creativo, porque su accionar revelaría el carácter ilusorio de las verdades. Así el mentiroso es condenado al destierro por abusar de las

\footnotetext{
55 Ibíd. Pág. 25.

${ }^{56}$ Cfr., lbíd. Pág. 20.

57 Ibíd. Pág. 25.
} 
convenciones y perjudicar con la mentira ya que "abusa de las convenciones consolidadas haciendo cambios discrecionales, cuando no invirtiendo los nombres. Si hace esto de manera interesada y que además ocasione perjuicios, la sociedad no confiará ya más en él y, por este motivo, lo expulsará de su seno" ${ }^{58}$

La facultad de olvido es necesaria para lograr que el consenso celebrado siga vigente y sea respetado por los miembros de la comunidad. El carácter ilusorio de este contrato queda así ocultado a fines de salvaguardar la vida. Develarlo sería correr un riesgo que puede atentar contra la conservación de la sociedad. El sentido epistemológico de esta forma de olvido queda así determinado como un modo de operar que pretende ocultar el origen convencional de las verdades que sirven como justificación de la existencia de una determinada forma de vida. El sentido político del olvido se solapa directamente al epistemológico, ya que al olvidar las condiciones de origen de las verdades éstas se vuelven vinculantes para los hombres.

En Sobre Verdad y Mentira en Sentido Extramoral los sentidos reactivos de la facultad de olvido aparecen como condición del empobrecimiento vital y de la conservación de formas de vida carentes de la fuerza suficiente para afirmarse. Funciona como un elemento que permite el proceso de abstracción y la consecuente creación de conceptos a través de la omisión de las particularidades. Asimismo, el olvido permite ocultar la función creadora del hombre al omitir que las metáforas son producidas por él mismo. También posibilita que una ficción se vuelva verdad y hacerla vinculante para los hombres a efectos de la conservación de la comunidad. De esta manera, vemos como en este texto el olvido es una función que emerge a partir de la debilidad vital para conservar la vida inhibiendo potencias creadoras.

\section{5.- Conclusiones preliminares}

La memoria, el olvido y su relación con la vida es compleja y contradictoria. Deleuze y Niemeyer se quedan sólo con la interpretación de La Genealogía de la Moral y

\footnotetext{
58 Ibíd. Pág. 21.
} 
no dan cuenta de los sentidos atribuidos en otras obras. Sostener que la memoria enferma la vida y el olvido la potencia puede servir para hacer una suerte de sistematización teórica, pero no puede ser una definición acabada de estos dos elementos. En la Segunda Consideración Intespestiva, a primera vista se podría interpretar a la "enfermedad histórica" como la memoria y el sentir ahistórico como el saludable olvido y así reproducir la matriz deleuziana, pero un examen más profundo del texto permite inferir la existencia de dos formas de apropiarse del pasado que pueden comprenderse como ejercicio de una memoria, pero que no enferma la vida. Tenemos aquí a la Historia Monumental, donde un aumento de poder se adueña del pasado creando sentido y la Historia Crítica, donde hay una memoria que destruye y juzga el pasado para liberarse.

Por otro lado, en Sobre Verdad y Mentira en Sentido Extramoral se presenta una concepción de olvido que lejos está de devolver la salud al cuerpo como sostenía Deleuze. En este escrito la facultad de olvidar responde a necesidades racionales que operan produciendo conceptos omitiendo las diferencias, el no recordar también interviene en contra de la vida al genera una confusión entre las metáforas producidas por el hombre y la "realidad" negando de esta manera actividad creativa que les dio origen. De esta forma, se logra establecer lo que ha de ser verdadero para la comunidad y que ejerce mayor coacción en cuanto mayor es el olvido de las circunstancias que le dieron origen.

La cuestión de la memoria y el olvido en el pensamiento nietzscheano se complejiza cuando se establecen relaciones con las fuerzas de la vida, sobre todo cuando se exploran los diferentes sentidos con que se presentan en distintas obras. Sin embargo, es posible afirmar que existe una doble relación de estas facultades con la vida: existen formas de memoria que debilitan la vida y otra que la favorece, lo mismo puede decirse del olvido. 
Nuevo Itinerario Revista Digital de Filosofía ISSN 1850-3578

2015 - Vol. 10 - Número X - Resistencia, Chaco, Argentina 